\title{
(2) OPEN ACCESS \\ Global palliative care research (2002-2020): bibliometric review and mapping analysis
}

\author{
Hammoda Abu-Odah (D) , Alex Molassiotis (D), Justina Yat Wa Liu
}

\begin{abstract}
- Additional online supplemental material is published online only. To view please visit the journal online (http://dx.doi.org/10.1136/ bmjspcare-2021-002982)

School of Nursing, The Hong Kong Polytechnic University, Kowloon, Hong Kong
\end{abstract}

\section{Correspondence to} Mr Hammoda Abu-Odah, The Hong Kong Polytechnic University, Kowloon, Hong Kong; hammoda.abuodah@connect. polyu.hk

Received 10 February 2021 Accepted 11 July 2021

\section{Check for updates}

(c) Author(s) (or their employer(s)) 2021. Re-use permitted under CC BY-NC. No commercial re-use. See rights and permissions. Published by BM.

\footnotetext{
To cite: Abu-Odah $\mathrm{H}_{\text {, }}$ Molassiotis A, Liu JYW. BMJ Supportive \& Palliative Care Epub ahead of print: [please include Day Month Year]. doi:10.1136/ bmjspcare-2021-002982
}

\section{ABSTRACT \\ Background and objective Despite the important benefits of a bibliometric approach on mapping a research field, relatively little efforts have previously been conducted to map and analyse the global trends of palliative care (PC)- related research. This bibliometric review aimed to provide an overall picture and systematic mapping of the state of research trends within the field of PC internationally.}

Methods Scopus and Web of Science databases were searched to retrieve original articles focusing on PC between 2002 and 2020. Searching was conducted on 5 May 2020, and was updated on 6 May 2021. All retrieved articles were assessed by title and abstract, and the bibliometric metadata of those that met the inclusion criteria were downloaded for analysis. The results were analysed by VOSviewer and Gephi software.

Results A total of 19,199 articles met the inclusion criteria. Significant growth of the number of published articles was reported by around five-fold from 2002 to 2020 . The USA and UK were the most productive countries in terms of the number of papers published and citations. Weak collaborations were observed between low-income or middle-income countries and high-income countries. Cancer-related PC research was the most common focus. Seven clusters of research were identified and included heart failure and cancer prognosis, nursing home, pain and symptoms management, PC knowledge and attitudes, quality improvement of services, PC ethics, and the ongoing assessment of PC services.

Conclusions There is a need to expand PCrelated research to non-cancer diseases. More international research and cross-institutional cooperation is required to address more global PC issues and benefit from wider sharing of expertees, potentially leading to higher quality or more impactful studies. Setting up research agendas and priorities from funding bodies and institutions may also enhance cooperation among researchers.

\section{Key messages}

\section{What was already known?}

- Most authors of palliative care publications are from North America and Europe

- Cancer-related palliative care research is the most common focus in the palliative care field in comparison with other disease types.

- The USA and UK take a leading contribution in palliative care research.

What are the new findings?

- There is minimal international cooperation across countries and within-country institutions in palliative care research.

- Weak collaborations are observed between low-income or middle-income countries and high-income countries.

- There is a paucity of research focusing on curriculum and education interventions, symptom management trials, quality indicators and ongoing palliative care, particularly for non-cancer life-limiting diseases.

What is their significance?

- Future research should focus on expanding palliative care-related research more on non-cancer diseases.

- More international research and crossinstitutional cooperations are required to address more global PC issues.

- Interventional research is necessary and should be directed towards managing the complexity of palliative care delivery.

- Setting up appropriate policies and strategies to support cooperation and facilitate the exchange of ideas about palliative care is required.

\section{INTRODUCTION}

A bibliometric review is an appropriate approach utilised for mapping a research field providing a comprehensive picture of the development and current status of a research field over a long period of time. ${ }^{1}$ This approach uses 'a set of quantitative 
methods to measure, track and analyse print-based scholarly literature' published over a long period. ${ }^{2}$ Bibliometric approaches process a large number of research published over a long period with a limited investment of resources and time. ${ }^{3}$ Bibliometric analysis produces measures of productivity (eg, numbers of published papers); impact (eg, number of citations, journal impact factors) and cooperation across countries, institutions and authors. ${ }^{4}$ It provides an understanding of the growth of scientific research and their trends within a specific field and contributes to the development of health initiatives. ${ }^{5}$ A bibliometric analysis is recognised as a statistical evaluation of published articles, and it is an effective way to measure the influence of publications in the scientific community. ${ }^{3}$ It portrays a primary step towards global mapping and classifying palliative care (PC)-related research, which may assist in understanding the commonalities of research, identify research gaps, set research agenda and map future research directions. A bibliometric analysis is based on using encoded bibliographic information available in scholarly databases ${ }^{4}$ for examining publication trends, the contribution of researchers, countries and institutions to the development of research through generating and visualising maps based on network. ${ }^{3}$

Although the use of a bibliometric approach on mapping a research field is important, relatively little efforts have previously been directed to map and analyse PC-related research trends. For instance, Walshe and $\mathrm{Ahmed}^{6}$ assessed the relation between contributing authors and PC-related journals to highlight geographical bias that may affect access to evidence. They found that most of the authors were from North America and Europe. They also showed that American authors published their papers more commonly in American journals and European authors published in European journals, lacking crossfertilisation of the available evidence. Cheong et al, ${ }^{7}$ mapped the PC-related articles published from inception until 2018 in the Asia Pacific Region. Findings revealed that out of 32 Asia Pacific countries, only 18 high-income countries (HICs) within this region published relevant research, and most of the published articles focused on cancer. Clark et al, ${ }^{8}$ mapped and synthesised the international PC-related research published from inception until 2013. They found that most research was from Europe. Most research focused on evaluation of services, policy-makers and policy-related issues. Liu et al,,$^{9}$ presented PC-related research trends from 2001 to 2016 and observed that the USA and UK took a leading contribution in PC research. Furthermore, Curiale ${ }^{10}$ mapped the global geriatric PC research in 2009. Results showed that most research was conducted in North America, and most of the published papers focused on advanced dementia and cancer. Despite the significant findings of previous studies, most of them limited their searches to articles in specific geographical settings. Moreover, the 'sample' included in the previous studies appeared to underrepresent the publications in the PC field as it was extracted from one database, being either Scopus or Web of Science (WOS) databases. Furthermore, all of the previous studies did not provide a comprehensive visualisation of PC-related research in the globe and did not use advanced programmes for mapping research that offers additional statistics such as degree of cooperation between countries, authors and institutions. Considering these limitations, previous studies did not offer a clear, representative and comprehensive picture of the state of research within the field of PC in the world.

Therefore, this bibliometric review is conducted to provide an updated overall picture and systematic mapping of the state of research trends within the field of PC from 2002 to 2020.The findings of this study indicate potential directions that the researchers, journals, institutions, and countries should consider for enhancing the PC field, and will highlight research fields that require further research attention.

\section{METHODS \\ Study design}

A bibliometric approach was employed to map the research literature on PC using metadata extracted from two databases over 18 years. Searching was conducted on 5 May 2020, and was updated on 6 May 2021.

\section{Search sources and strategies}

Searches were performed on Scopus and WOS, being the largest, ${ }^{11}$ most comprehensive and multidisciplinary databases utilised in this type of review. Both databases provide different citation impact metrics such as Field-Weighted Citation Impact to indicate the impact of a publication. They cover literature in the field of biomedical and social sciences. Scopus also covers $100 \%$ of Medline material. ${ }^{12}$

The search strategy of this review is based on the following terms, including 'palliative care' with its alternative search keywords ('palliat"', 'palliative medicine', 'hospice care', 'terminal care', 'end-of-life care', end of life care, 'life-limiting', 'life-threatening', and 'incurable disease') combined with the Boolean operator 'OR' for generating a large number of results, performed with the help of a university librarian. The terms were used for screening the title and the abstract to identify relevant papers. The search was limited to original articles published in English language between 1 January 2002 and 31 December 2020. The detailed search strategies and search results for both databases is presented in online supplemental table $\mathrm{S} 1$.

Inclusion criteria for considering papers in this review

- Original articles only. 
- Articles clearly stating 'PC' or its alternative search keywords in their title and abstract.

- Published in or after 2002.

- Written in English.

\section{Study selection and data extraction}

The function 'relevance' in both databases was chosen to sort articles that most closely matched with the searched terms making easier to assess and screen articles. Titles and abstracts of articles were assessed by the first author, and those that did not meet the criteria were excluded after discussion with the second author. The final articles included from both databases were exported into 'Comma- Separated Values' file, which was subsequently utilised to remove duplicates based on each paper's digital object identifier. Reasons for excluding articles were identified and documented in online supplemental figure S1.

\section{Data analysis and visualisation}

Before analysing the results, all inconsistencies in the bibliometric data, including names of journals and references, were adjusted and corrected. The analysis of the bibliometric metadata covers two main pillars, which include performance analysis and science mapping. ${ }^{13}$ Performance analysis aims to assess authors such as the year of publication, the number of citations, the productivity and impact of institution, country, journal and the impact of cited publications. Productivity is assessed by the number of publications, while the number of citations is an indicator of importance relevance ${ }^{14}$ and impact of publications. When studying the annual trend of PC-related publications, exponential smoothing with Brown's linear trend was adopted to forecast the number of annual publications for the next 5 years. Included countries were categorised by income level, where low-income and middle-income economy countries (LMICs) refer to developing countries, and high income ones refer to developed countries. ${ }^{15}$ Identifying the geographic region of the journal is based on where the journal is hosted/based, acknowledging that the editorial boards of such journals and the content they publish is often wider or have more global coverage.

Gaining such information helps to find relevant literature and to support decision making regarding where to publish. Authors were converted to rank order by Standard competition ranking. The top 15 ranked authors were considered for further visualisation and presentation. Different values such as Impact Factor (IF) and SCImago Journal Rank were used for ranking and prioritising the authors.

Science mapping aims to explore the interrelation between institutions, disciplines, fields or specialities to draw content-related conclusions. ${ }^{13}$ Two software packages (VOSviewer (V.1.6.13) and Gephi (0.0.2)) were used for science mapping of PC research outputs. VOSviewer is a free software that allows researchers to generate and visualise maps easily. ${ }^{16}$ It is used to construct and visualise bibliometric maps according to network data. ${ }^{16}$ It was used for conducting a series of coauthorship analyses, including patterns of cooperation between countries and institutions by measuring occurrence/frequency and total link strength, which are used for measuring patterns of directions. For instance, in keywords analysis, total link strength reveals the publications' number in which two keywords occur together. Cooperation across countries/institutions was categories into weak and strong, where weak cooperation means that the work between countries in PC related research is minimal (Have little collaboration). It can be determined by measuring the link between nodes such as countries. The thick link between nodes is representing strong cooperation across countries.

Gephi V.0.0.2 is another free software for visualisation and analysis of large network graphs. ${ }^{17}$ It was used in this study to estimate values such as centrality and betweenness centrality, which are commonly used criteria for analysing coauthorship. ${ }^{18}$ Degree centrality is the most straightforward approach which presents the number of relations a node has to other nodes. ${ }^{18}$ It is calculated by counting how many neighbours a node has. ${ }^{18}$ Betweenness centrality was calculated to estimate which nodes are more influenced when two or more nodes have the same equal value. ${ }^{17} 18$ It was used to measure the number of times a node lies on the shortest path between nodes. ${ }^{17} 18$

\section{RESULTS}

\section{Selection of studies}

The literature search yielded 29,298 papers indexed in Scopus and WOS between 1 January 2002 and 31 December 2020. Of these, 16447 duplicates were removed, leaving 19694 papers for the title and abstract screening. An additional 495 papers (245 were reviews, 90 were abstracts only, 79 were conference papers, and 81 papers were written in a language other than English) were excluded. Thus, the final number included in this review were 19,199 (online supplemental figure S1).

\section{Performance analysis}

The annual trend of PC publications

Significant growth in the number of published articles was reported in the past decade, reaching the highest peak in the year 2016 with 1838 articles. A slight decrease was noted in 2017 with 1495 articles. The 2020 publications were 1874 articles. The quantity of publications has increased by around fourfold from 2002 to 2020 and is forecasted to increase to 2470 papers in 2025, an 19\% 5-year increase (figure 1).

Contribution of journals

Articles were published in 2987 journals. Ninety-four per cent $(n=2815)$ of journals published no more than 


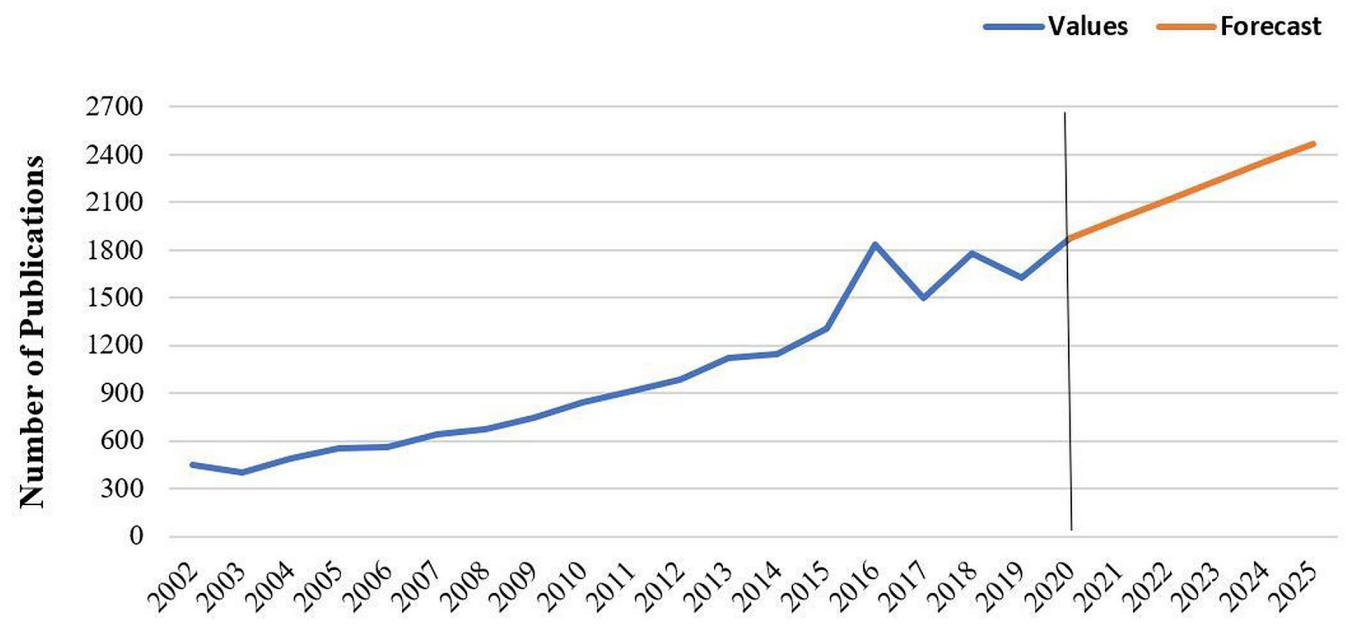

Publication Year

Figure 1 The annual trend of palliative care-related publications.

15 PC-related articles in total. $35.7 \%$ of the publications $(6,827$ articles) were published in the 'top' 15 journals. These journals have published most PC research papers. Most of these top journals were from North America and Europe. The 'Journal of Palliative Medicine', whose IF in 2020 was 2.085, ranked first in terms of the number of publications in PC with a total of 1236 articles (6.4\%). 'Journal of Clinical Oncology' and 'Palliative Medicine' had the highest IF in 2020 (32.956 and 3.739, respectively), while two journals had no IF and were not listed in the journal citation report 2020 (table 1). Overall, the 'Journal of Palliative Medicine', 'Journal of Pain and Symptom Management' and 'Palliative Medicine' were the top three journals that published most PC articles between 2002 and 2020.

Geographical origin of articles and their citations average

Articles were published from 142 countries. The most significant number of articles was from HICs, including the USA $(31.53 \%)$, followed by the UK (12.58\%), Canada (8.26\%) and Australia (6.25\%). The lowest number was from China (1.64\%), Belgium $(1.82 \%)$ and South Korea (1.93\%). When the data of the top 15 countries were stratified by number of articles per million of population using the formula: (number of articles/population $\times 10$ ), ${ }^{19}$ Australia and

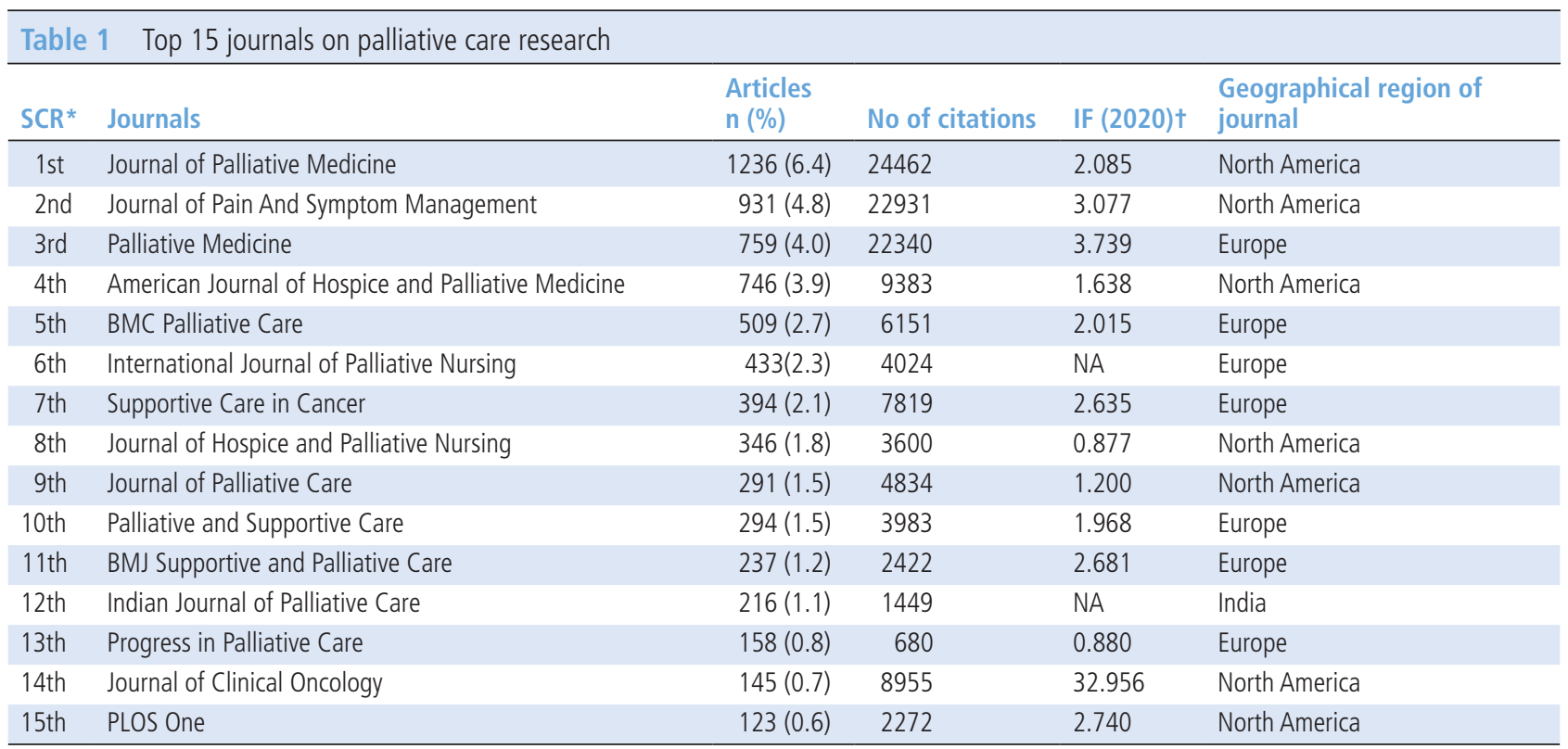

*Equal journals have the same ranking number and then the gap is left in the ranking numbers.

tIF was reported according to ISI JCR 2020.

IF, impact factor; JCR, journal citation report; NA, not available; SCR, standard competition ranking.; 
Table 2 Top 15 most productive countries on palliative care research

\begin{tabular}{|c|c|c|c|c|c|c|}
\hline Rank & Country & No of articles & $\begin{array}{l}\text { Percentage of } \\
\text { articles published } \\
\text { by country }\end{array}$ & No of citations & $\begin{array}{l}\text { Population (in } \\
\text { Millions) }\end{array}$ & $\begin{array}{l}\text { No of articles } \\
\text { per million } \\
\text { population }\end{array}$ \\
\hline 1 & USA & 6029 & 31.53 & 146989 & 329.8 & 18.3 \\
\hline 2 & UK & 2406 & 12.58 & 51794 & 67.5 & 35.6 \\
\hline 3 & Canada & 1582 & 8.26 & 38970 & 37.4 & 42.3 \\
\hline 4 & Australia & 1195 & 6.25 & 25812 & 25.2 & 47.4 \\
\hline 5 & Germany & 808 & 4.22 & 17106 & 83.5 & 9.7 \\
\hline 6 & Japan & 704 & 3.68 & 10425 & 126.8 & 5.5 \\
\hline 7 & Netherlands & 665 & 3.49 & 18299 & 17.1 & 39.1 \\
\hline 8 & Italy & 559 & $2.92 \%$ & 12413 & 60.5 & 9.2 \\
\hline 9 & Sweden & 470 & 2.45 & 9119 & 10.0 & 47.0 \\
\hline 10 & France & 427 & 2.33 & 7402 & 65.1 & 6.5 \\
\hline 11 & India & 427 & 2.33 & 4612 & 1366.4 & 0.3 \\
\hline 12 & Spain & 398 & 2.08 & 7858 & 46.7 & 8.5 \\
\hline 13 & South Korea & 369 & 1.93 & 6610 & 51.2 & 7.2 \\
\hline 14 & Belgium & 348 & 1.82 & 6195 & 11.5 & 30.3 \\
\hline 15 & China & 314 & 1.64 & 4522 & 1433.7 & 0.2 \\
\hline
\end{tabular}

Sweden (47/million) ranked first followed by Canada (40.7/million) and the UK (35.5/million).

Findings also showed that the total number of citations between 2002 and 2020 was 291112 with an average of 15.2 citations per each article. The highest citations average was 50.4 for articles from USA and 17.79 for articles from the UK. The lowest citations (0.15) was reported in articles from India. Although India ranked eleventh in the number of articles published $(=427)$, the overall performance in terms of citations average was low. In contrast, Belgium ranked 14 th in the number of articles published $(=348)$, but the citation average $(=2.13)$ ranked 11th (table 2$)$.

\section{Highly cited PC articles and their content}

This section focused on the top 15 articles with the most citations. Highly cited articles are shown in table 3. There were more than six authors in most of the fifteen highly cited articles. All articles were coauthored. Fourteen publications were completed through cooperation between institutions. Cooperations were limited mostly to institutions within the same country. There were minimal international cooperations between institutions, and only one publication was accomplished by international cooperation across three countries.

Our findings revealed that the most cited paper was by Temel et al. ${ }^{20}$ In this paper, the authors examined the effect of early introduction of PC in newly diagnosed patients with metastatic non-small-cell lung cancer at the end of life. The work of Detering et al, ${ }^{21}$ occupied the second position. This paper shed light on older adults, and how advance care planning impacted on their end-of-life care. The paper ranked third was conducted by Teno et al, ${ }^{22}$ to evaluate the family's perspectives on dying experience at both home and institutional settings in the USA. Other highly cited articles focused on clinical outcomes in patients with advanced cancer, quality of spiritual care, bereavement in the family, satisfaction with care and costs, and communication skills (table 3 ).

\section{Science mapping: the structure of the body of knowledge} on PC

Keywords co-occurrence analysis

Out of 20501 keywords extracted from Scopus, 63 keywords met the criteria to have a minimum number of 60 occurrences. This criterion was based on multiple trials to generate a reliable, optimal, controllable and producible network. The final network consisted of 65 nodes and 1176 relations, with an average of 18 relations reflecting the co-occurrence between PC as a primary term and keywords representing other areas (figure 2).

For identifying the main research areas in the field over the study period, the occurrences and total link of strength of keywords that were listed in a paper were measured. The most common areas that have acquired a growing interest in the field from 2002 to 2020 were related to cancer, paediatric, quality of life and pain. After 2014, most current PC-related research focused on heart problems and dementia-related areas, education and training. The majority of PC-related education focused on assessment of healthcare professionals' knowledge, competency and needs in PC, perception and attitudes (table 4). However, other areas have remained under-researched being represented by keywords such as burn-out, dysphagia, palliative chemotherapy and treatment, symptoms management and general practice. Most frequently study keywords in PC by years is presented in online supplemental table S2. 


\begin{tabular}{|c|c|c|c|c|c|c|c|c|}
\hline $\mathrm{SCR}^{*}$ & $\begin{array}{l}\text { Authors and years of } \\
\text { publication }\end{array}$ & Title & Journal & $\begin{array}{l}\text { Citation- } \\
\text { Scopus }\end{array}$ & $\begin{array}{l}\text { Citation- } \\
\text { WOS }\end{array}$ & $\mathrm{NI}$ & NC & $\begin{array}{l}\text { Country of } \\
\text { research }\end{array}$ \\
\hline $1 \mathrm{st}$ & Temel et al, $2010^{20}$ & $\begin{array}{l}\text { Early palliative care for patients with metastatic } \\
\text { non-small-cell lung cancer }\end{array}$ & $\begin{array}{l}\text { New England Journal of } \\
\text { Medicine }\end{array}$ & 4216 & 3816 & 4 & 1 & USA \\
\hline 2nd & Detering et al, $2010^{21}$ & $\begin{array}{l}\text { The impact of advance care planning on end } \\
\text { of life care in elderly patients: Randomised } \\
\text { controlled trial }\end{array}$ & British Medical Journal & 1248 & 1147 & 2 & 1 & Australia \\
\hline $3 r d$ & Teno et al, $2004^{22}$ & $\begin{array}{l}\text { Family Perspectives on End-of-Life Care at the } \\
\text { Last Place of Care }\end{array}$ & $\begin{array}{l}\text { Journal of the American } \\
\text { Medical Association }\end{array}$ & 1125 & 998 & 3 & 1 & USA \\
\hline 4th & Mitchell et al, $2011^{56}$ & $\begin{array}{l}\text { Prevalence of depression, anxiety, and } \\
\text { adjustment disorder in oncological, } \\
\text { haematological, and palliative-care settings: A } \\
\text { meta-analysis of } 94 \text { interview-based studies }\end{array}$ & The Lancet Oncology & 1120 & 1009 & 6 & 3 & UK \\
\hline 5th & Bakitas et al, $2009^{57}$ & $\begin{array}{l}\text { Effects of a palliative care intervention on } \\
\text { clinical outcomes in patients with advanced } \\
\text { cancer: The project ENABLE II randomised } \\
\text { controlled trial }\end{array}$ & $\begin{array}{l}\text { Journal of the American } \\
\text { Medical Association }\end{array}$ & 1002 & 927 & 9 & 1 & USA \\
\hline 6th & $\begin{array}{l}\text { Zimmermann et al, } \\
2014^{58}\end{array}$ & $\begin{array}{l}\text { Early palliative care for patients with advanced } \\
\text { cancer: A cluster-randomised controlled trial. }\end{array}$ & The Lancet & 847 & 783 & 6 & 1 & Canada \\
\hline 7th & Harstell et al, $2005^{59}$ & $\begin{array}{l}\text { Randomized trial of short- versus long-course } \\
\text { radiotherapy for palliation of painful bone } \\
\text { metastases }\end{array}$ & $\begin{array}{l}\text { Journal of the National } \\
\text { Cancer Institute }\end{array}$ & 567 & 478 & 3 & 1 & USA \\
\hline 8th & Morrison et al, $2008^{60}$ & $\begin{array}{l}\text { Cost savings associated with US hospital } \\
\text { palliative care consultation programs }\end{array}$ & $\begin{array}{l}\text { Archives of Internal } \\
\text { Medicine }\end{array}$ & 552 & 497 & 7 & 1 & USA \\
\hline 9th & Brumley et al, $2007^{61}$ & $\begin{array}{l}\text { Increased satisfaction with care and lower } \\
\text { costs: Results of a randomised trial of in-home } \\
\text { palliative care }\end{array}$ & $\begin{array}{l}\text { Journal of the American } \\
\text { Geriatrics Society }\end{array}$ & 547 & 492 & 5 & 1 & USA \\
\hline 10th & Bakitas et al, $2015^{62}$ & $\begin{array}{l}\text { Early versus delayed initiation of concurrent } \\
\text { palliative oncology care: Patient outcomes in the } \\
\text { ENABLE III randomised controlled trial }\end{array}$ & $\begin{array}{l}\text { Journal of Clinical } \\
\text { Oncology }\end{array}$ & 536 & 514 & 6 & 1 & USA \\
\hline 11th & Back et al, $2007^{63}$ & $\begin{array}{l}\text { Efficacy of communication skills training for } \\
\text { giving bad news and discussing transitions to } \\
\text { palliative care }\end{array}$ & $\begin{array}{l}\text { Archives of Internal } \\
\text { Medicine }\end{array}$ & 498 & 461 & 11 & 1 & USA \\
\hline 12th & Heyland et al, $2006^{64}$ & $\begin{array}{l}\text { What matters most in end-of-life care: } \\
\text { Perceptions of seriously ill patients and their } \\
\text { family members }\end{array}$ & $\begin{array}{l}\text { Canadian Medical } \\
\text { Association Journal }\end{array}$ & 425 & 351 & 10 & 1 & Canada \\
\hline 13th & Temel et al, $2011^{65}$ & $\begin{array}{l}\text { Longitudinal perceptions of prognosis and goals } \\
\text { of therapy in patients with metastatic non- } \\
\text { small-cell lung cancer: Results of a randomised } \\
\text { study of early palliative care }\end{array}$ & $\begin{array}{l}\text { Journal of Clinical } \\
\text { Oncology }\end{array}$ & 416 & 378 & 3 & 1 & USA \\
\hline 14th & Gade et al, $2008^{66}$ & $\begin{array}{l}\text { Impact of an inpatient palliative care team: A } \\
\text { randomised control trial }\end{array}$ & $\begin{array}{l}\text { Journal of Palliative } \\
\text { Medicine }\end{array}$ & 382 & 359 & 11 & 1 & USA \\
\hline 15 th & Schulz et al, $2003^{67}$ & $\begin{array}{l}\text { End-of-Life Care and the Effects of Bereavement } \\
\text { on Family Caregivers of Persons with Dementia }\end{array}$ & $\begin{array}{l}\text { New England Journal of } \\
\text { Medicine }\end{array}$ & 381 & 311 & 1 & 1 & USA \\
\hline
\end{tabular}

${ }^{*}$ Equal articles have the same ranking number andthen the gap is left in the ranking numbers.

NC, number of countries affiliated in a paper; NI, number of institutions affiliated in a paper; SCR, standard competition ranking; WOS, Web of Science.

Country coauthorship analysis (collaborations between or within countries)

Of 141 countries identified, 43 countries met the criterion of having a minimum number of 40 occurrences for a country. Weighted degree values were calculated to identify and rank the top cooperating countries in the PC field (figure 3). Findings revealed that the UK stands out as the top-ranked country with respect to cooperation in research on PC. The USA was the main centre in North America, Australia was the key research centre in Asia, South Korea in East Asia, India in South Asia, Uganda in Africa, and Israel in the Middle East region. However, the strength of relations with other countries were not strong, particularly with LMICs that have strived towards improvements in PC over the years (online supplemental figure S2). Weak cooperation was observed with Malaysia, Thailand, Nigeria, Turkey, Iran, Saudi Arabia, Egypt, Taiwan, Hong Kong, Mexico and Kenya. It is noted that the most cooperation was among HICs, particularly those leading in PC development in terms of quality of PC services and longest history in establishing PC.

The institution co-authorship analysis

Of 58420 institutions identified, 74 institutions met the criterion of having a minimum number of 10 occurrences. Hyperlink-induced topic search was calculated using Gephi software to identify the top influential institutions in the PC field. Findings reported few collaborative relationships across institutions in PC research. Cooperations were noted in USA, Australia, 


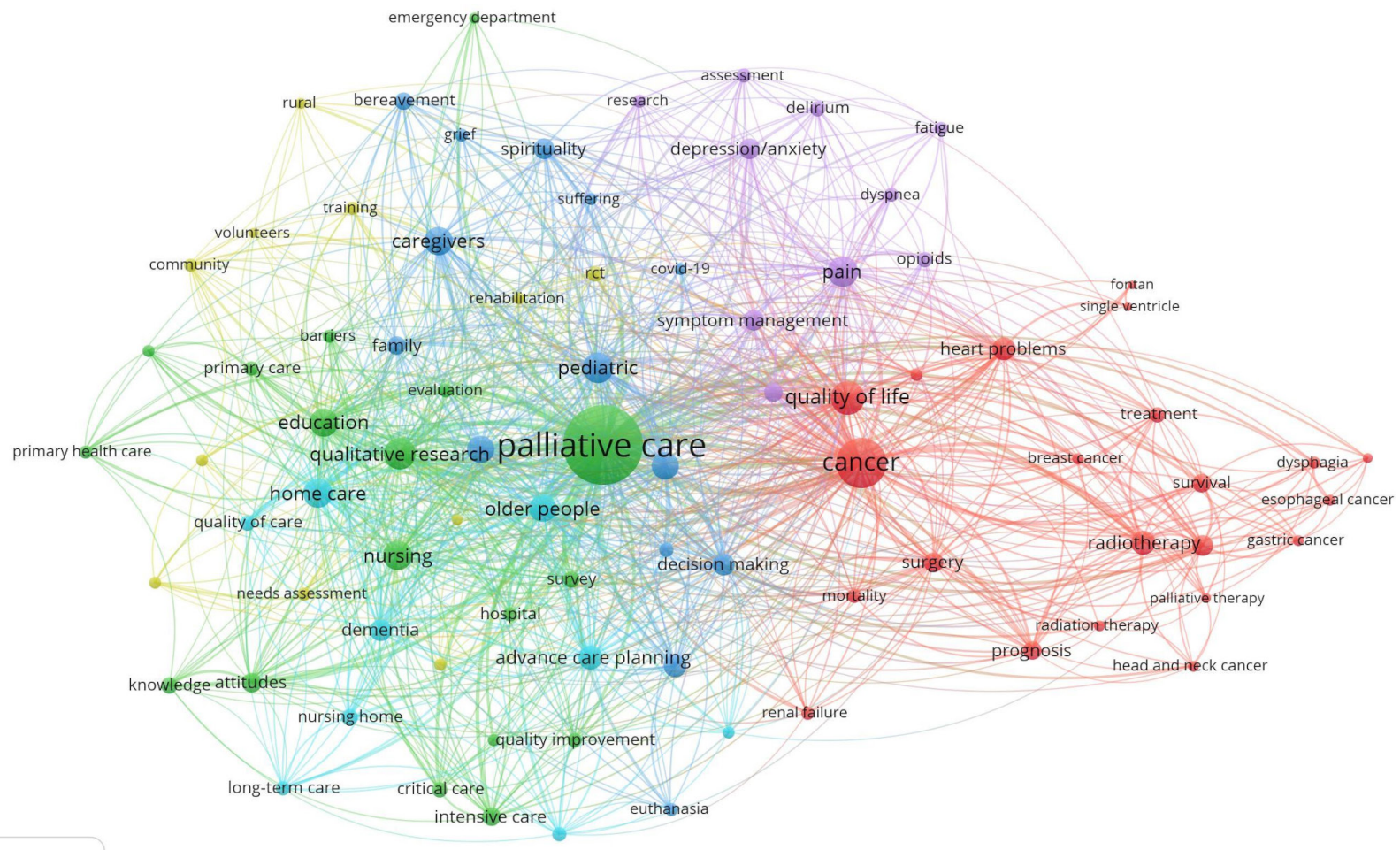

B Vosviewer

Figure 2 Keywords co-occurrence network of PC-related publications. PC, palliative care.

Canada, Uganda, South Korea, Belgium, Netherlands and Denmark. The cooperations were not as strong, as displayed by the thickness of the lines connecting the institutions. A strong international collaborative was noted between African institutions ((African Palliative Care Association (APCA), and Hospice Africa Uganda)) and International USA Association ((International Association for Hospice and Palliative Care) as well as with King's College London, UK. Also, strong cooperation was reported between Harvard University, USA with Duke University, Flinders University and Southern Adelaide Palliative Services, Australia. However, lack of cooperation was observed among many institutions, and their cooperations were restricted only on institutions within the same country (online supplemental figure S3).

Table 4 Most frequently study keywords in palliative care by years

\begin{tabular}{|c|c|c|c|c|c|c|c|c|c|}
\hline \multirow[b]{2}{*}{ Rank } & \multirow[b]{2}{*}{ Keyword } & \multicolumn{2}{|c|}{ 2002-2008 } & \multicolumn{2}{|c|}{ 2009-2014 } & \multicolumn{2}{|c|}{ 2015-2020 } & \multicolumn{2}{|c|}{$\begin{array}{c}\text { Total 2002-31 December, } \\
2020\end{array}$} \\
\hline & & Occurrences & $\begin{array}{l}\text { Total link } \\
\text { strength }\end{array}$ & Occurrences & $\begin{array}{l}\text { Total link } \\
\text { strength }\end{array}$ & Occurrences & $\begin{array}{l}\text { Total link } \\
\text { strength }\end{array}$ & Occurrences & $\begin{array}{l}\text { Total link } \\
\text { strength }\end{array}$ \\
\hline 1 & Cancer & 71 & 273 & 519 & 993 & 1073 & 1823 & 1933 & 3028 \\
\hline 2 & Paediatric & 14 & 54 & 171 & 274 & 428 & 581 & 667 & 865 \\
\hline 3 & Quality of life & 19 & 76 & 186 & 404 & 327 & 632 & 624 & 1102 \\
\hline 4 & Pain & 29 & 121 & 190 & 416 & 272 & 444 & 565 & 935 \\
\hline 5 & Qualitative research & 11 & 48 & 128 & 275 & 361 & 692 & 538 & 962 \\
\hline 6 & Education & 21 & 74 & 111 & 223 & 285 & 476 & 462 & 750 \\
\hline 7 & Heart problems & 17 & 56 & 130 & 161 & 247 & 253 & 440 & 421 \\
\hline 8 & Home care & 12 & 54 & 112 & 236 & 258 & 533 & 439 & 817 \\
\hline 9 & Nursing & 5 & 24 & 127 & 292 & 236 & 490 & 418 & 836 \\
\hline 10 & Radiotherapy & 16 & 49 & 110 & 172 & 192 & 222 & 399 & 472 \\
\hline 11 & Caregivers & 12 & 54 & 83 & 195 & 265 & 539 & 394 & 740 \\
\hline 12 & Older people & 9 & 35 & 110 & 247 & 210 & 433 & 369 & 699 \\
\hline 13 & Death and dying & 22 & 85 & 100 & 234 & 170 & 346 & 363 & 693 \\
\hline 14 & Communication & 4 & 16 & 112 & 249 & 212 & 427 & 351 & 675 \\
\hline 15 & Chemotherapy & 11 & 45 & 90 & 121 & 165 & 206 & 295 & 341 \\
\hline
\end{tabular}




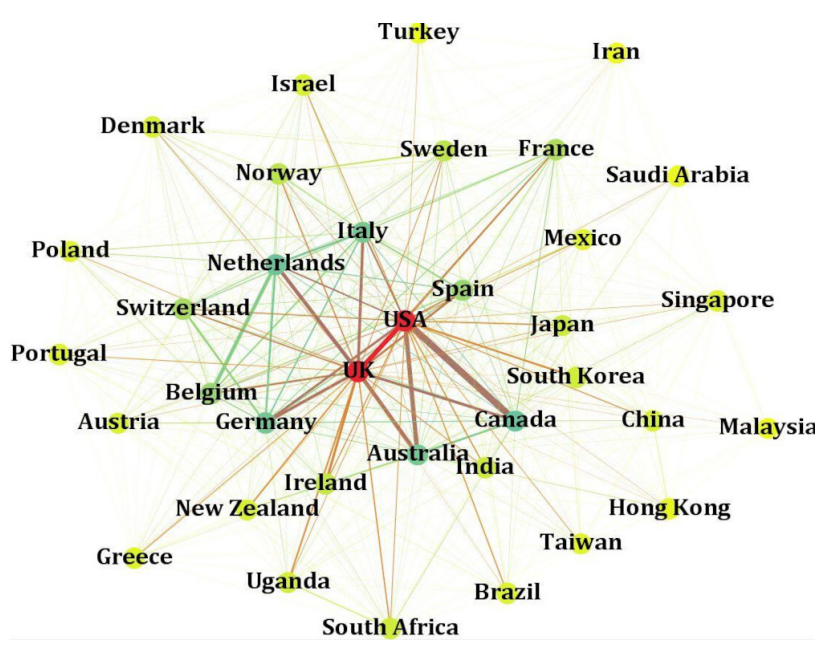

Figure 3 Cooperation network of countries in palliative care research.

\section{Clustering and labelling of PC research}

By using VOSviewer, filtering out small size clusters that included less than five keyword occurrences, the current body of knowledge on PC generated a network with major clusters (table 5). As per the cluster sizes, cluster \#1, which was labelled 'chronic heart failure and cancer prognosis' was the most significant clusters in the literature that ranked first and contained 16 keywords, followed by cluster \#2, which was labelled 'nursing home' and contained 15 keywords. The pain and symptom management cluster was third, including ten keywords (online supplemental figure S4).

\section{DISCUSSION}

This is the first bibliometric review that has provided an overall picture and systematic mapping of global PC-related research between 2002 and 2020. Our analysis revealed significant expansion of PC-related research, particularly from 2015 onwards. These findings are in line with past research. ${ }^{9}$ There are several possible explanations for this result. It might be related to the ageing world population and increasing demand for PC. ${ }^{23}$ It could be linked to responding countries to the WHO's PC policy calls. ${ }^{24}$ It also might be associated with PC being formally recognised as a medical specialty from several countries more recently. ${ }^{25}$

It is not surprising that the most significant number of articles was from North America and Europe because more than half of the top 15 authors contributing to PC field are working in institutions in the USA and the UK, suggesting that American and British researchers have taken the leading contribution in the PC field. This result is congruent with Walshe and Ahmed recent study. ${ }^{6}$ The USA has a long history of PC development, and it has witnessed a rapidly growing provision of $\mathrm{PC}$ within its healthcare system more recently. ${ }^{26}$ For instance, in 2010, two-thirds of USA hospitals offered PC. ${ }^{26}$ High productivity of PC-related publications in USA, the UK, Australia and Canada might be attributed to the study's inclusion criteria that limited analysis only on English language articles. Publications in other languages such as Chinese, Korean, German and Spanish would be more frequent and useful for scholars and other practitioners in Latin America. ${ }^{27}$ High productivity might be related to the country of reviewers, editors, and investigators, as most of them are from North America and Europe. ${ }^{6}$ Furthermore the congresses and meetings held by these three regional organisations (APCA, European Association for Palliative Care (EAPC) and Asia Pacific Hospice Palliative Care Network) are mostly in English while the congresses of the Latin American Association for Palliative Care are in Spanish and Portuguese. This may also be a

\begin{tabular}{|c|c|c|c|c|}
\hline Cluster-ID & Narrative description of the content & $\begin{array}{l}\text { Keywords no } \\
\text { in the cluster }\end{array}$ & Colour of cluster & Cluster (Label) \\
\hline$\# 1$ & $\begin{array}{l}\text { This cluster focused on two main diseases: cancer and heart disease. The } \\
\text { words included chemotherapy, dysphagia, mortality, outcomes, prognosis, } \\
\text { QOL, radiotherapy, surgery, survival, single ventricle, treatment. }\end{array}$ & 16 & Red & $\begin{array}{l}\text { Chronic heart failure } \\
\text { and cancer prognosis }\end{array}$ \\
\hline \#2 & $\begin{array}{l}\text { The words in this cluster shed light on nursing, care planning, dementia, } \\
\text { home care, long-term care, nursing home, older people, quality of care. }\end{array}$ & 15 & Green & Nursing home \\
\hline \#3 & $\begin{array}{l}\text { The words in this cluster shed light on pain and symptom related issues such } \\
\text { as assessment, delirium, anxiety and depression, dyspnoea, opioid, pain, } \\
\text { symptom management. }\end{array}$ & 10 & Blue & $\begin{array}{l}\text { Pain and symptom } \\
\text { management }\end{array}$ \\
\hline \#4 & $\begin{array}{l}\text { The word in this cluster summarised the attitudes and knowledge about } \\
\text { end-of-life care-related issues, including critical care, quality improvement, } \\
\text { decision making, nursing, survey }\end{array}$ & 9 & Yellow & $\begin{array}{l}\text { Knowledge and } \\
\text { Attitudes toward end- } \\
\text { of-life care }\end{array}$ \\
\hline$\# 5$ & $\begin{array}{l}\text { This cluster focused on evaluation and quality improvement of services. It } \\
\text { included terms such as hospital, intensive care, evaluation, quality. }\end{array}$ & 5 & Purple & $\begin{array}{l}\text { Quality improvement } \\
\text { of services }\end{array}$ \\
\hline$\# 6$ & Communication, decision making, ethics, euthanasia. & 5 & Ginzary & Palliative care ethics \\
\hline$\# 7$ & $\begin{array}{l}\text { This cluster contains words that focused on ongoing assessment of the } \\
\text { services. It covers keywords such as community, health services research, } \\
\text { primary care, public health,. }\end{array}$ & 5 & Orange & $\begin{array}{l}\text { Ongoing assessment } \\
\text { of palliative care } \\
\text { services }\end{array}$ \\
\hline
\end{tabular}


contributing factor to more publications in English from these regions.

Although there is an increasing number of published articles in some countries, their research citations remain low. This finding is in agreement with the National Science Board $^{28}$ report findings, which showed high frequency published papers with low citation. The increasing number of publications seen particularly in India may be attributed to India's regulations that obligate post-graduate students to publish papers in indexed journals. ${ }^{29}$ Such regulations on conducting research help drive PC development which is observed in India ${ }^{30}$ that have witnessed successful growth of PC in recent years. Research is, therefore, an essential component of $\mathrm{PC}^{31}$ which plays a significant role in developing PC globally. Considerable efforts are required in focusing on innovation and building research capacity in the future, particularly in LMICs that seek on developing PC at a national level.

Study findings also highlighted that most PC journals' IF was down in 2020 compared with previous years. IF reflects the importance of a journal by measuring the yearly average number of citations published in the last 2 years in a journal. ${ }^{32}$ The higher the journals' IF, the better the journal. ${ }^{32}$ Several factors influence journals' IF such as the number of papers published and an average number of citations. ${ }^{33}$ The lower IF of PC journals' might be related to increasing publication output in recent years. Increasing publication output does not always translate to better quality papers published or more citations, which may be one of the reasons for a decreased IF in several PC journals last year.

The cooperation between scholars was limited. Minimal international cooperation was observed across countries and within institutions. International cooperation in health research is a quintessential mechanism for promoting knowledge, increasing research capacity and achieving breakthrough results. ${ }^{34} \mathrm{~A}$ possible explanation for these results might be the differing priorities of research between developed and LMICs. Another explanation is that most sponsoring/ funding institutions are focusing on research related to their priorities in a single country. ${ }^{35}$ Thus, there is an urgent need to establish an international network, share ideas, and ensure transparency for increasing partnerships and setting research agendas. Such processes are led by international institutions such as the APCA and the EAPC. For instance, EAPC plays a pivotal role in supporting and organising global scientific and educational events/conferences, aiming at increasing cooperation between scholars globally, bringing together those who study and practice the PC-related issues, sharing ideas, and updating knowledge-related PC. ${ }^{36}$ Despite the focus of the EAPC in Europe, it also aims at enhancing PC in LMICs through the exchange of information and expertise. ${ }^{36}$ More collaboration on PC-related research between scholars in both within and across HICs and LMICs are required for enhancing PC services and quality of care. These can be established by setting appropriate policies and strategies that support cooperation and facilitate the exchange of ideas about PC.

Although PC is a comprehensive approach focusing on all patients with life-limiting conditions, ${ }^{37}$ the majority of PC-related research focuses on adult cancerrelated issues within the study period (2002-2020). The results are consistent with past research. ${ }^{38}$ Adult cancer patients are the larger group of patients with life-limiting illnesses, often experiencing a wide range of symptoms that impact their needs. ${ }^{39}$ More attention to cancer was further observed after 2014. This might be attributed to countries' response to WHO's call on implementing polices to ensure the development of PC services within countries' healthcare system, as cancer is often the focus of countries when developing their PC services. ${ }^{40}$ Our study findings also show that most PC-related research still focused on education, services provision, quality of life and pain-related issues. These results are in line with a systematic review that assessed priorities of the international PC research in $2020 .{ }^{41}$ Enhancing patients' quality of life and comfort is PC's primary goal. ${ }^{42} \mathrm{PC}$ aims at relieving serious health related suffering. ${ }^{42}$ After 2015, major PC-related research shifted its focus to dementia-related areas. Transitional demographic changes and increasing the life expectancy in population might be the reasons for the increasing focus of PC in dementia more recently. ${ }^{43}$ It might be attributed to the growing number of people diagnosed with dementia. ${ }^{44}$ By 2050 , the number of people diagnosed with dementia is expected to increase significantly, reaching 125 million globally. ${ }^{45}$ A small number of studies have focused on other life-limiting diseases such as respiratory diseases, kidney diseases, HIV, Parkinson's, stroke and liver diseases. Further studies, which take these disease types into account, will need to be undertaken. While our search covered a period of a few early months into COVID-19 and indeed a small number of such papers was included in the list of identified studies, COVID-19 as a potentially life-threatening disease may be a new focus of PC research in the near future.

Pain-related issues are still one of the major focus of PC-related research. PC isused to ease pain and other associated symptoms such as physical, social, emotional and psychological symptoms. Availability and affordability of pain-relief medication is required while patients receiving PC, as pain management is critical component in PC services. Unavailability of and poor access to pain-relief medicationare unique challenges to the provision of PC in LMICs. ${ }^{46}$ Over $80 \%$ of the patients with PC needs in LMICs have limited or no access to such medication. ${ }^{47}$ This high percentage should be considered while developing PC in LMICs. 
Findings also highlighted that 141 countries out of 195 countries globally had published papers related to PC. This means there are no PC publications from about onequarter (54 countries) of the world countries, primarily LMICs where they may have significant PC needs and often outside the cancer context.

PC education has been recognised as the key step towards improving healthcare professionals' knowledge, attitudes and skills. ${ }^{48}$ That is why this topic has frequently been reported in past studies, although most of the studies focused on educational assessments. Very little was found in the literature on interventional studies and curriculum evaluations, particularly for those non-cancer life-limiting diseases as reported in Meekin et $a l^{49}$ study. Further work is required in this area.

Most patients with life-limiting diseases develop potentially devastating symptoms during their disease trajectory. ${ }^{50}$ In this study, most papers focused on managing specific symptoms, particularly anxiety, depression, pain and delirium; however, other crucial symptoms in a PC context such as constipation, cough, dyspnoea, xerostomia, nausea, vomiting and fever ${ }^{50}$ were not a key focus in the list of common keywords analysed. Future studies on many such symptoms are therefore recommended.

Survival and mortality topics have not received adequate research attention in PC too. However, other topic focus on general practitioners (GPs) and quality indicators need further research attention. GPs play a pivotal role in providing $\mathrm{PC}$ in the community. ${ }^{51}$ Many GPs are not confident and comfortable with PC when working in community settings and particularly when confronted with dying patients because of their inadequate level of skills and insufficient knowledge. ${ }^{52}$ Further research should be done in this area to deliver best practice PC such as the role of GPs in delivering $\mathrm{PC}$ to patients. Other areas such as assessing GP performance on working more effectively in the community, their knowledge and attitudes towards PC, and communication skills with patients are also necessary.

Measuring the quality of care which is provided to end-of-life patients is an important indicator enabling HCPs and policymakers to monitor and enhance care provision. $^{53}$ Quality indicators can identify good care and potential problems. ${ }^{54}$ Although this topic is important; only limited attention has been paid to quality indicators for the care provided to patients with life-threatening conditions as reported in this study. Further research should focus on the different types of quality indicators, including process, structure and outcomes.

\section{Strengths and limitations}

This review is subject to several limitations such as limiting searches only on original papers available at Scopus and WOS databases. The search was restricted only to papers written in English, and this limits generalisability. In addition, the searches were based on specific keywords clearly stated in title and abstract of the paper; this might have not included all papers related to $\mathrm{PC}$ in this review.

Adopting the frequency of common keywords appearing on papers as a way to assess the direction of PC-related research, rather than indicating the research focus of articles, might be another limitation in this study which could mislead the future direction of PC-related research and be perhaps a linguistic indicator. Furthermore, assessing the quality of papers based only on their citations is also another limitation in this study as it is difficult to appraise a large number of papers and quality of each paper is not the purpose of a bibliometric analysis, which is focusing on outcome metrics. Meanwhile, it is not easy to assess in-depth all papers included in terms of their research type, sample size, which is another limitation in this study. Furthermore, another limitation may be the use of only two databases, as the analysis packages used require harmonised databases to be merged, a complex task to be done with multiple databases (and indeed most bibliographic analyses in the past tend to use a single database only because of this).

\section{CONCLUSIONS}

This bibliometric review portrays a primary step towards global mapping and classifying PC-related research in the globe. There is a need to expand PC-related research more on non-cancer diseases to overcome their increasing complexity of care with population growth. More international research and cross-institutional cooperation are required, particularly also focusing on LMICs and their specific research agendas. Setting up research agendas and priorities from funding bodies and organisations may also enhance cooperation among researchers. Also, it is likely that research capacity building can enhance both research quality and the volume of collaborative research, and this may be an important way to improve quality, quantity and impact of research, as shown in work in the UK. ${ }^{55}$

Contributors Study design, literature search, data extraction and checking, data analysis and interpretation, and manuscript drafting and revision: HA-O and AM; Study conception and design, and manuscript revision: AM and JL. Manuscript revision: HA-O, AM, JL. Drafting initial paper: HA-O; Contribution in the discussion and final write-up: all authors; All authors approved the final manuscript.

Funding The authors have not declared a specific grant for this research from any funding agency in the public, commercial or not-for-profit sectors.

Competing interests None declared.

Patient consent for publication Not required.

Provenance and peer review Not commissioned; externally peer reviewed.

Open access This is an open access article distributed in accordance with the Creative Commons Attribution Non Commercial (CC BY-NC 4.0) license, which permits others to distribute, remix, adapt, build upon this work non-

commercially, and license their derivative works on different 
terms, provided the original work is properly cited, appropriate credit is given, any changes made indicated, and the use is noncommercial. See: http://creativecommons.org/licenses/by-nc/4. $0 /$.

\section{ORCID iDs}

Hammoda Abu-Odah http://orcid.org/0000-0002-8874-2599

Alex Molassiotis http://orcid.org/0000-0001-6351-9991

\section{REFERENCES}

1 Porter AL, Kongthon A, Lu Jye-Chyi (JC). Research profiling: improving the literature review. Scientometrics 2002;53:351-70.

2 Roemer RC, Borchardt R. Meaningful metrics: A 21st-century librarian's guide to bibliometrics, altmetrics, and research impact. American Library Association, 2015.

3 Andrés A. Measuring academic research: how to undertake a bibliometric study. Chandos Publishing. Elsevier, 2009.

4 Haddow G. Measuring academic research: how to undertake a bibliometric study. Library Management, 2010: 370-2.

5 Arunachalam S, Gunasekaran S. Tuberculosis research in India and China: from bibliometrics to research policy. Current Science 2002;82:933-47.

6 Walshe C, Ahmed F, Preston N. Do journals contribute to the International publication of research in their field? A bibliometric analysis of palliative care Journal data. Palliat Med 2020;34:541-6.

7 Cheong WL, Mohan D, Warren N, et al. Palliative care research in the Asia Pacific region: a systematic review and bibliometric analysis of peer-reviewed publications. J Palliat Med 2019;22:545-52.

8 Clark J, Gardiner C, Barnes A. International palliative care research in the context of global development: a systematic mapping review. BMJ Support Palliat Care 2018;8:7-18.

9 Liu C-J, Yeh T-C, Hsu S-H, et al. Bibliometric analysis of palliative care-related publication trends during 2001 to 2016. Am J Hosp Palliat Care 2018;35:1280-6.

10 Curiale V. World-Wide literature survey on geriatric palliative medicine. Eur Geriatr Med 2011;2:6-11.

11 Martín-Martín A, Orduna-Malea E, Thelwall M, et al. Google Scholar, web of science, and Scopus: a systematic comparison of citations in 252 subject categories. J Informetr 2018;12:1160-77.

12 Salisbury L. Web of science and Scopus: a comparative review of content and searching capabilities. The Charleston Advisor 2009;11:5-18.

13 van Eck NJ, Waltman L, Networks VB. Visualizing Bibliometric Networks. In: Ding Y, Rousseau R, Wolfram D, eds. Measuring scholarly impact: methods and practice. Cham: Springer International, 2014: 285-320.

14 Garfield E. Is citation analysis a legitimate evaluation tool? Scientometrics 1979;1:359-75.

15 Advocates for international developement. Understanding the developed/developing country taxonomy, 2020. Available: http://www.a4id.org/policy/understanding-thedevelopeddeveloping-country-taxonomy/ [Accessed 21 Jan 2021].

16 van Eck NJ, Waltman L. Software survey: VOSviewer, a computer program for bibliometric mapping. Scientometrics 2010;84:523-38.

17 Gephi. Gephi tutorial quick start, 2010. Available: https:// gephi.org/tutorials/gephi-tutorial-quick_start.pdf [Accessed 24 Apr 2020].

18 Gómez S. Centrality in networks: finding the most important nodes. In: Moscato P, de Vries NJ, eds. Business and consumer analytics: new ideas. Cham: Springer International Publishing, 2019: 401-33.

19 Nation U. World population prospects: the 2019 revision, 2019. Available: https://population.un.org/wpp/Download/ Standard/Population/ [Accessed 30 Oct 2020].
20 Temel JS, Greer JA, Muzikansky A, et al. Early palliative care for patients with metastatic non-small-cell lung cancer. N Engl J Med 2010;363:733-42.

21 Detering KM, Hancock AD, Reade MC, et al. The impact of advance care planning on end of life care in elderly patients: randomised controlled trial. BMJ 2010;340:c1345.

22 Teno JM, Clarridge BR, Casey V, et al. Family perspectives on end-of-life care at the last place of care. JAMA 2004;291:88-93.

23 Lupu D, Quigley L, Mehfoud N, et al. The growing demand for hospice and palliative medicine physicians: will the supply keep up? J Pain Symptom Manage 2018;55:1216-23.

24 World Health Organization. Strengthening of palliative care as a component of integrated treatment throughout the life course. J Pain Palliat Care Pharmacother 2014;28:130-4.

25 Bolognesi D, Centeno-Cortes C, Biasco G. Specialisation in palliative medicine for physicians in Europe 2014. In: A supplement of the EAPC atlas of palliative care in Europe Milan. European Association for Palliative Care, 2014.

26 Hughes MT, Smith TJ, Mark TH. The growth of palliative care in the United States. Annu Rev Public Health 2014;35:459-75.

27 Payne SA, Turner JM. Research methodologies in palliative care: a bibliometric analysis. Palliat Med 2008;22:336-42.

28 Board NS. Science \& Engineering Indicators 2018, 2018. Available: https://www.nsf.gov/statistics/2018/nsb20181/assets/ nsb20181.pdf [Accessed 25 May 2020].

29 Medical Council of India. Postgraduate medical education regulations, 2018.

30 Bhatnagar S. Palliative care research: Indian perspective. Indian J Palliat Care 2014;20:167-8.

31 Hannon B, Zimmermann C, Knaul FM, et al. Provision of palliative care in low- and middle-income countries: overcoming obstacles for effective treatment delivery. J Clin Oncol 2016;34:62-8.

32 Garfield E. The history and meaning of the Journal impact factor. JAMA 2006;295:90-3.

33 Kiesslich T, Weineck SB, Koelblinger D. Reasons for Journal impact factor changes: influence of changing source items. PLoS One 2016;11:e0154199.

34 Meslin EM, Garba I. International Collaboration for Global Public Health. In: Public health ethics: cases spanning the globe. Springer, Cham, 2016: 241-84.

35 Isaakidis P, Swingler GH, Pienaar E, et al. Relation between burden of disease and randomised evidence in sub-Saharan Africa: survey of research. BMJ 2002;324:702.

36 European Association of Palliative Care. Our history, 2020. Available: https://www.eapcnet.eu/our-history/ [Accessed 5 Feb 2020].

37 World Health Organization. WHO definition of palliative care, 2002.

38 Moral-Munoz JA, Carballo-Costa L, Herrera-Viedma $\mathrm{E}$, et al. Production trends, collaboration, and main topics of the integrative and complementary oncology research area: a bibliometric analysis. Integr Cancer Ther 2019;18:1534735419846401.

39 Abu Hamad B, Skaik N, Abu-Odah H. Evaluation of palliative care services provided to cancer patients in the Gaza strip. JUCMS 2016:95-107.

40 Connor SR, Bermedo S, Cecilia M. Global atlas of palliative care at the end of life, 2018.

41 Hasson F, Nicholson E, Muldrew D, et al. International palliative care research priorities: a systematic review. $B M C$ Palliat Care 2020;19:16.

42 World Health Organization. National cancer control programs: policies and managerial guidelines. 2 edn. Geneva: WHO, 2002.

43 Atella V, Piano Mortari A, Kopinska J, et al. Trends in agerelated disease burden and healthcare utilization. Aging Cell 2019;18:e12861-e61. 
44 Lillyman S, Bruce M. Palliative care for people with dementia: a literature review. Int J Palliat Nurs 2016;22:76-81.

45 Alzheimer's Disease International. Dementia facts \& figures, 2020. Available: https://www.alzint.org/about/dementia-factsfigures/ [Accessed 5 Feb 2020].

46 Abu-Odah H, Molassiotis A, Liu J. Challenges on the provision of palliative care for patients with cancer in low- and middleincome countries: a systematic review of reviews. BMC Palliat Care 2020;19:55.

47 Knaul F, Frenk J, Shulman L. Closing the cancer divide: a blueprint to expand access in low and middle income countries. Boston, MA: Harvard Global Equity Initiative, 2011.

48 Dalberg T, McNinch NL, Friebert S. Perceptions of barriers and facilitators to early integration of pediatric palliative care: a national survey of pediatric oncology providers. Pediatr Blood Cancer 2018;65:e26996.

49 Meekin SA, Klein JE, Fleischman AR, et al. Development of a palliative education assessment tool for medical student education. Acad Med 2000;75:986-92.

50 Blinderman CD, Billings JA. Comfort care for patients dying in the hospital. N Engl J Med 2015;373:2549-61.

51 Ramanayake RPJC, Dilanka GVA, Premasiri LWSS. Palliative care; role of family physicians. J Family Med Prim Care 2016;5:234-7.

52 Lim C, Berry ABL, Hirsch T, et al. "It just seems outside my health": How Patients with Chronic Conditions Perceive Communication Boundaries with Providers. DIS 2016;2016:1172-84.

53 McCorry NK, O'Connor S, Leemans K, et al. Quality indicators for palliative day services: a modified Delphi study. Palliat Med 2019;33:197-205.

54 De Roo ML, Leemans K, Claessen SJJ, et al. Quality indicators for palliative care: update of a systematic review. J Pain Symptom Manage 2013;46:556-72.

55 Payne S, Seymour J, Grande G, et al. An evaluation of research capacity building from the cancer experiences collaborative. BMJ Support Palliat Care 2012;2:280-5.

56 Mitchell AJ, Chan M, Bhatti H, et al. Prevalence of depression, anxiety, and adjustment disorder in oncological, haematological, and palliative-care settings: a meta-analysis of 94 Interview-Based studies. Lancet Oncol 2011;12:160-74.
57 Bakitas M, Lyons KD, Hegel MT, et al. Effects of a palliative care intervention on clinical outcomes in patients with advanced cancer: the project enable II randomized controlled trial. JAMA 2009;302:741-9.

58 Zimmermann C, Swami N, Krzyzanowska M, et al. Early palliative care for patients with advanced cancer: a clusterrandomised controlled trial. Lancet 2014;383:1721-30.

59 Hartsell WF, Scott CB, Bruner DW, et al. Randomized trial of short- versus long-course radiotherapy for palliation of painful bone metastases. J Natl Cancer Inst 2005;97:798-804.

60 Morrison RS, Penrod JD, Cassel JB, et al. Palliative care leadership centers' outcomes group. cost savings associated with us Hospital palliative care consultation programs. Archives of internal medicine 2008;168:1783-90.

61 Brumley R, Enguidanos S, Jamison P, et al. Increased satisfaction with care and lower costs: results of a randomized trial of in-home palliative care. J Am Geriatr Soc 2007;55:993-1000.

62 Bakitas MA, Tosteson TD, Li Z, et al. Early versus delayed initiation of concurrent palliative oncology care: patient outcomes in the enable III randomized controlled trial. J Clin Oncol 2015;33:1438-45.

63 Back AL, Arnold RM, Baile WF, et al. Efficacy of communication skills training for giving bad news and discussing transitions to palliative care. Arch Intern Med 2007;167:453-60.

64 Heyland DK, Dodek P, Rocker G, et al. What matters most in end-of-life care: perceptions of seriously ill patients and their family members. CMAJ 2006;174:627-33.

65 Temel JS, Greer JA, Admane S, et al. Longitudinal perceptions of prognosis and goals of therapy in patients with metastatic non-small-cell lung cancer: results of a randomized study of early palliative care. J Clin Oncol 2011;29:2319-26.

66 Gade G, Venohr I, Conner D, et al. Impact of an inpatient palliative care team: a randomized control trial. J Palliat Med 2008;11:180-90.

67 Schulz R, Mendelsohn AB, Haley WE, et al. End-Of-Life care and the effects of bereavement on family caregivers of persons with dementia. N Engl J Med 2003;349:1936-42. 